\title{
Three-Dimensional Laser-Assisted Patterning of Blue-Emissive Metal Halide Perovskite Nanocrystals inside a Glass with Switchable Photoluminescence
}

Xiongjian Huang, Qianyi Guo, Shiliang Kang, Tianchang Ouyang, Qinpeng Chen, Xiaofeng Liu, Zhiguo Xia, Zhongmin Yang, Qinyuan Zhang, Jianrong Qiu, Guoping Dong*

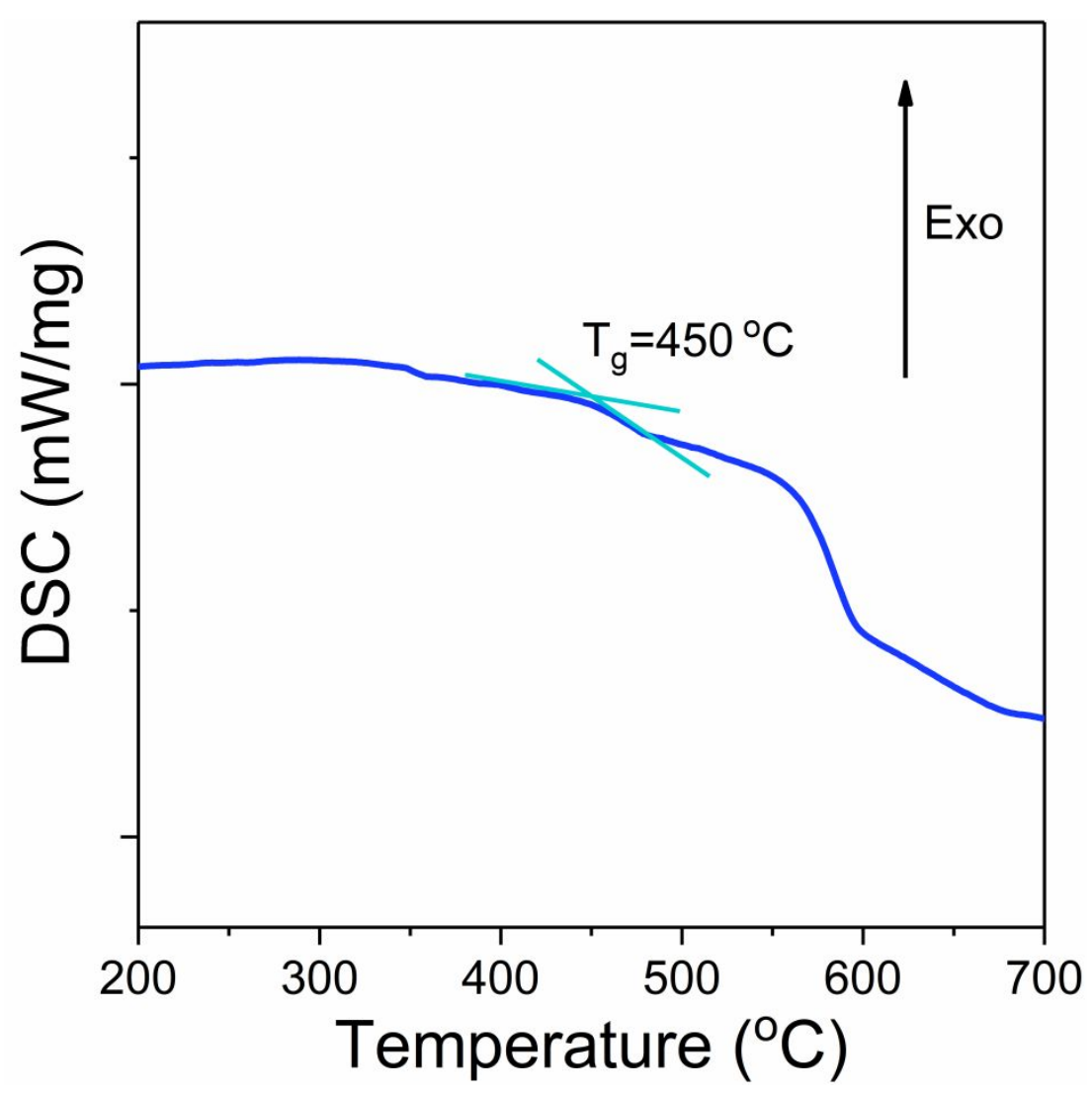

Figure S1. DSC curve of precursor glass. The glass transition temperature is located at approximately $450{ }^{\circ} \mathrm{C}$ and the glass softening temperature is $570{ }^{\circ} \mathrm{C}$. No obvious crystallization peak is observed at temperature up to $700{ }^{\circ} \mathrm{C}$. 


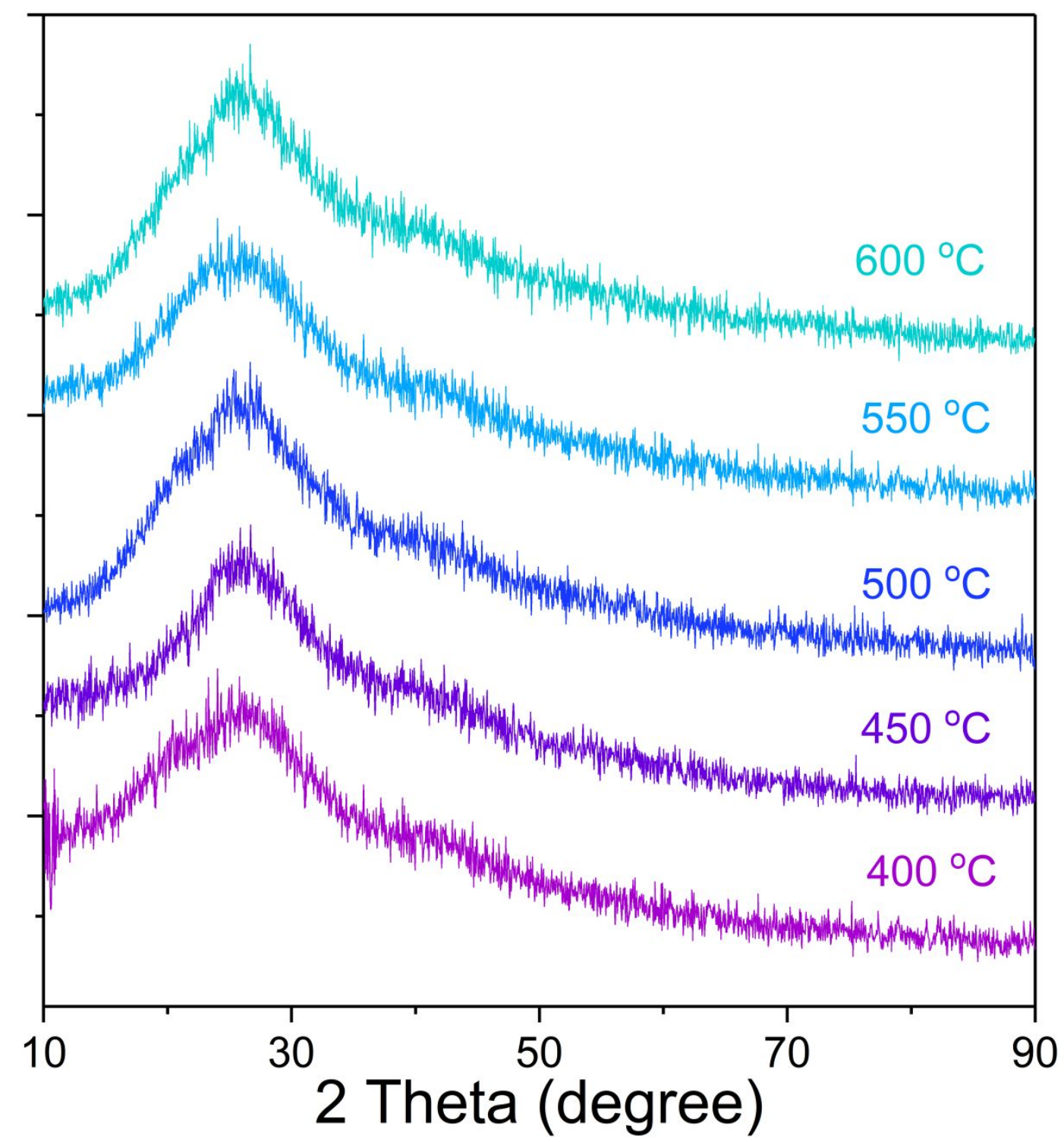

Figure S2. XRD patterns of the glass samples (without fs laser irradiation) after thermal treatment between $400{ }^{\circ} \mathrm{C}$ and $600{ }^{\circ} \mathrm{C}$ for 5 hours. No obvious crystal diffraction peak is detected at annealing temperature up to $600{ }^{\circ} \mathrm{C}$ (higher than the glass softening temperature and the glass plate became distorted at this temperature), which indicates that $\mathrm{CsPb}(\mathrm{Cl} / \mathrm{Br})_{3}$ NCs or other crystallites can not be formed by direct thermal treatment. 


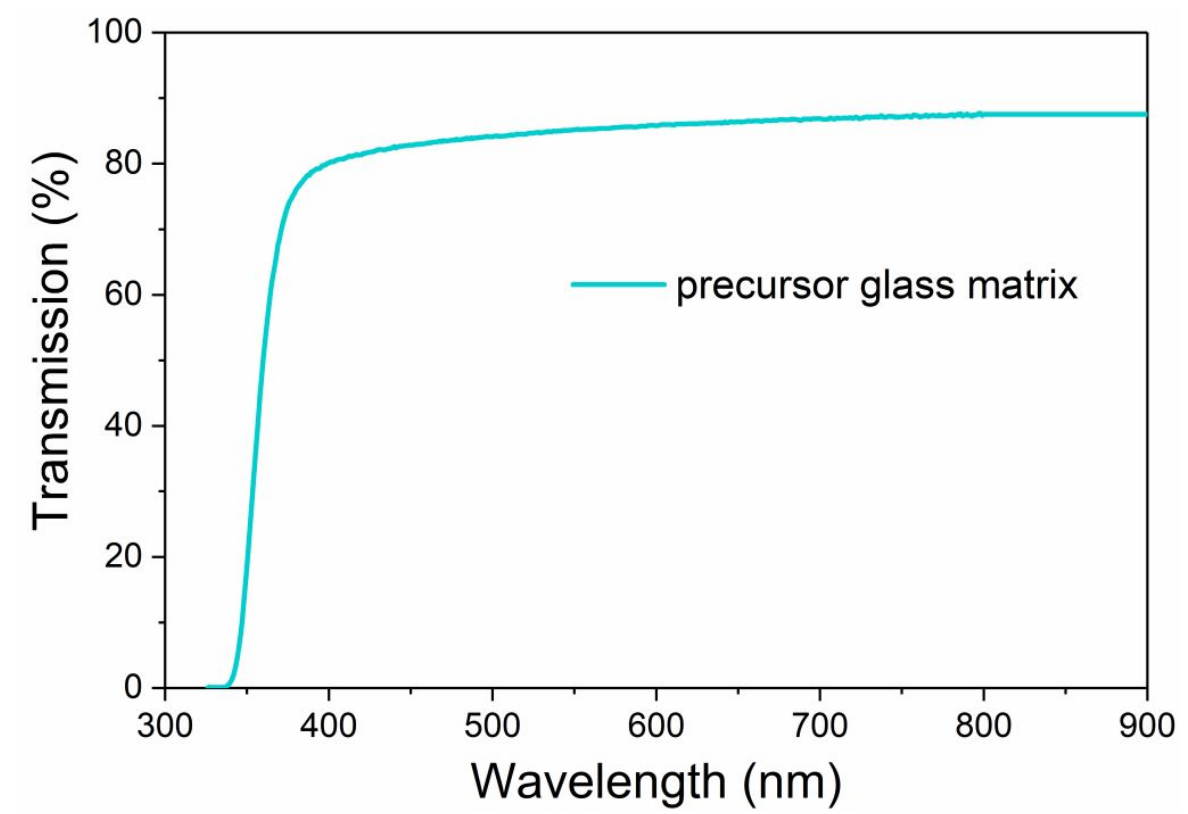

Figure S3. Transmission spectrum of the precursor glass. The high transparency among 400 $\mathrm{nm}$ to $900 \mathrm{~nm}$ indicates that the glass matrix can not be interacted with continuous-wave laser through linear absorption. The linear absorption coefficient of the glass sample at $800 \mathrm{~nm}$ is $1.547 \mathrm{~cm}^{-1}$. But fs laser with a central wavelength at $800 \mathrm{~nm}$ can induce the glass through nonlinear absorption by multiphoton processes.

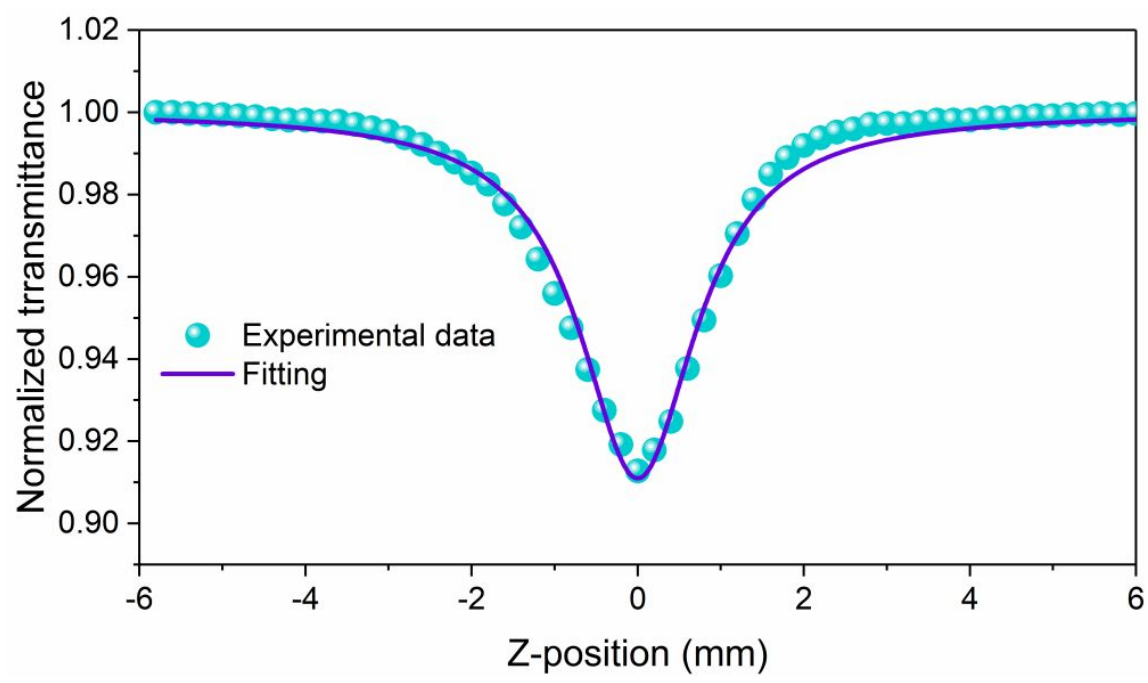

Figure S4. Typical Z-scan curve of the glass sample. The data were fitted by nonlinear absorption model according to the nonlinear optical theory. ${ }^{1}$ The nonlinear absorption coefficient at $800 \mathrm{~nm}$ is $1.26 \times 10^{-11} \mathrm{~cm} / \mathrm{W}$. 

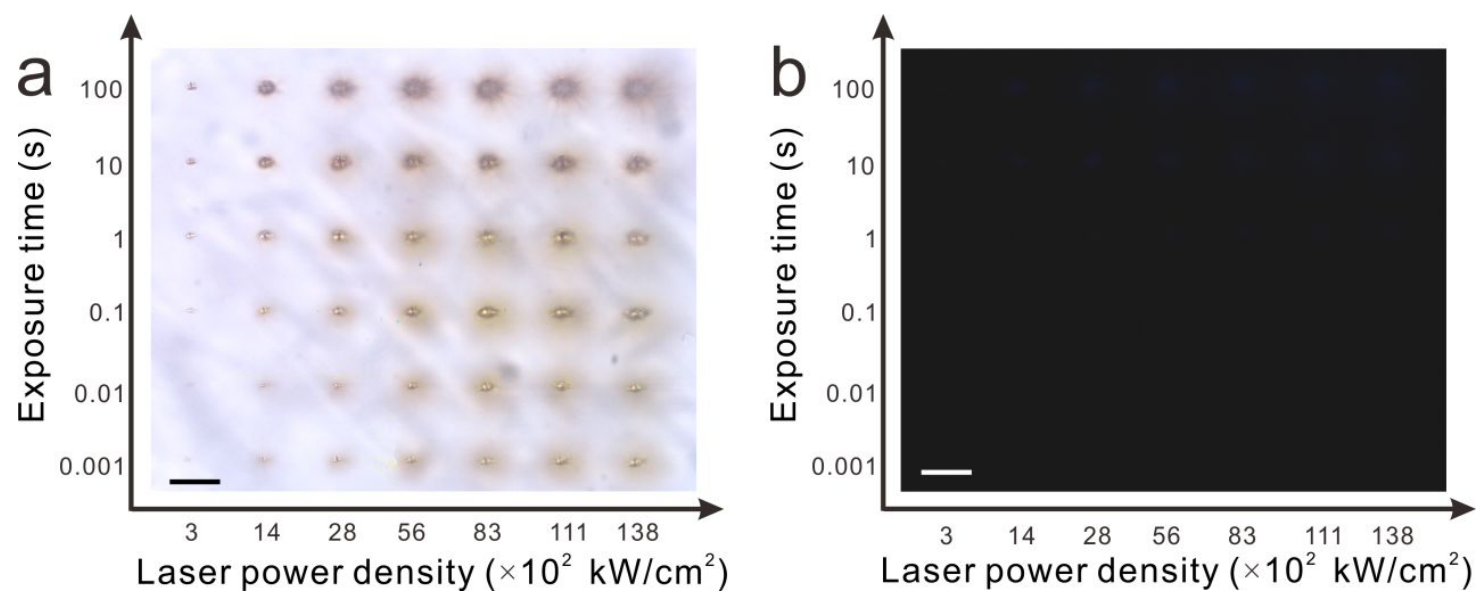

Figure S5. a,b) Optical images taken under a) visible light and b) $365 \mathrm{~nm}$ UV light for laserirradiated regions (before thermal treatment) fabricated using different laser power density and exposure time. Scale bar: $100 \mu \mathrm{m}$. Very weak blue emissions can be observed at the laserirradiated regions, indicating that a few $\mathrm{CsPb}(\mathrm{Cl} / \mathrm{Br})_{3} \mathrm{NCs}$ or crystal nuclei are formed by fs laser irradiation before thermal treatment.

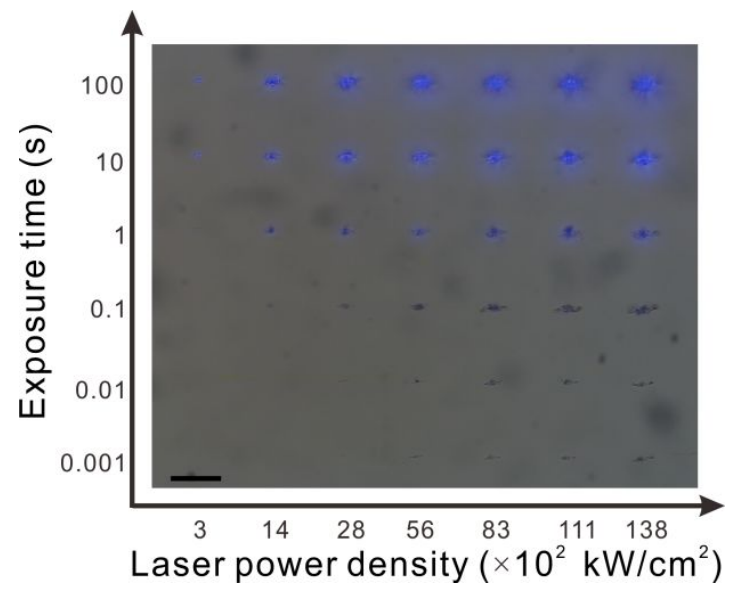

Figure S6. Optical images taken under natural light and $365 \mathrm{~nm}$ UV light at the same time for laser-irradiated regions generated by using different laser power density and exposure time,. The glass samples were thermally treated at $450{ }^{\circ} \mathrm{C}$ after laser irradiation. Scale bar: $100 \mu \mathrm{m}$. 


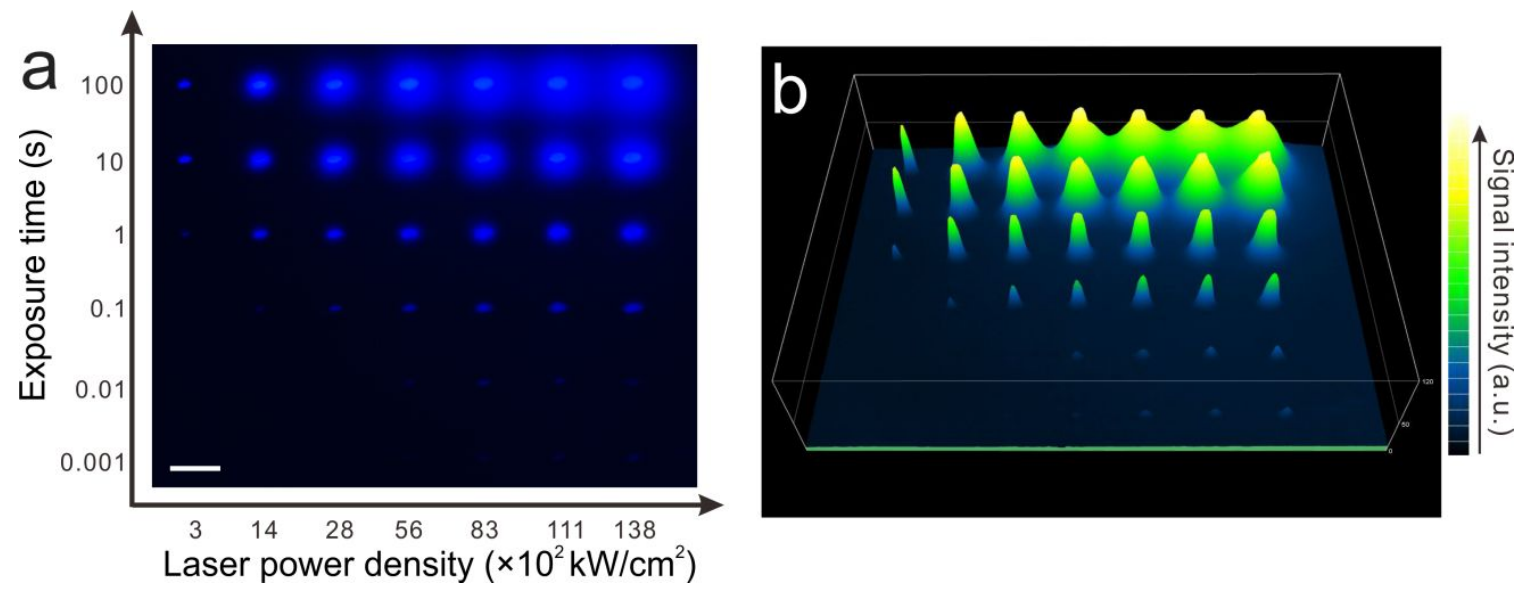

Figure S7. a), Optical images taken under $365 \mathrm{~nm}$ UV light for laser-irradiated regions generated by using different laser power density and exposure time. The glass samples were thermally treated at $450{ }^{\circ} \mathrm{C}$ after laser irradiation. Scale bar: $100 \mu \mathrm{m}$. b) Emission signal intensity map corresponding to a). The power of UV light for excitation is $2 \mathrm{~W}$.

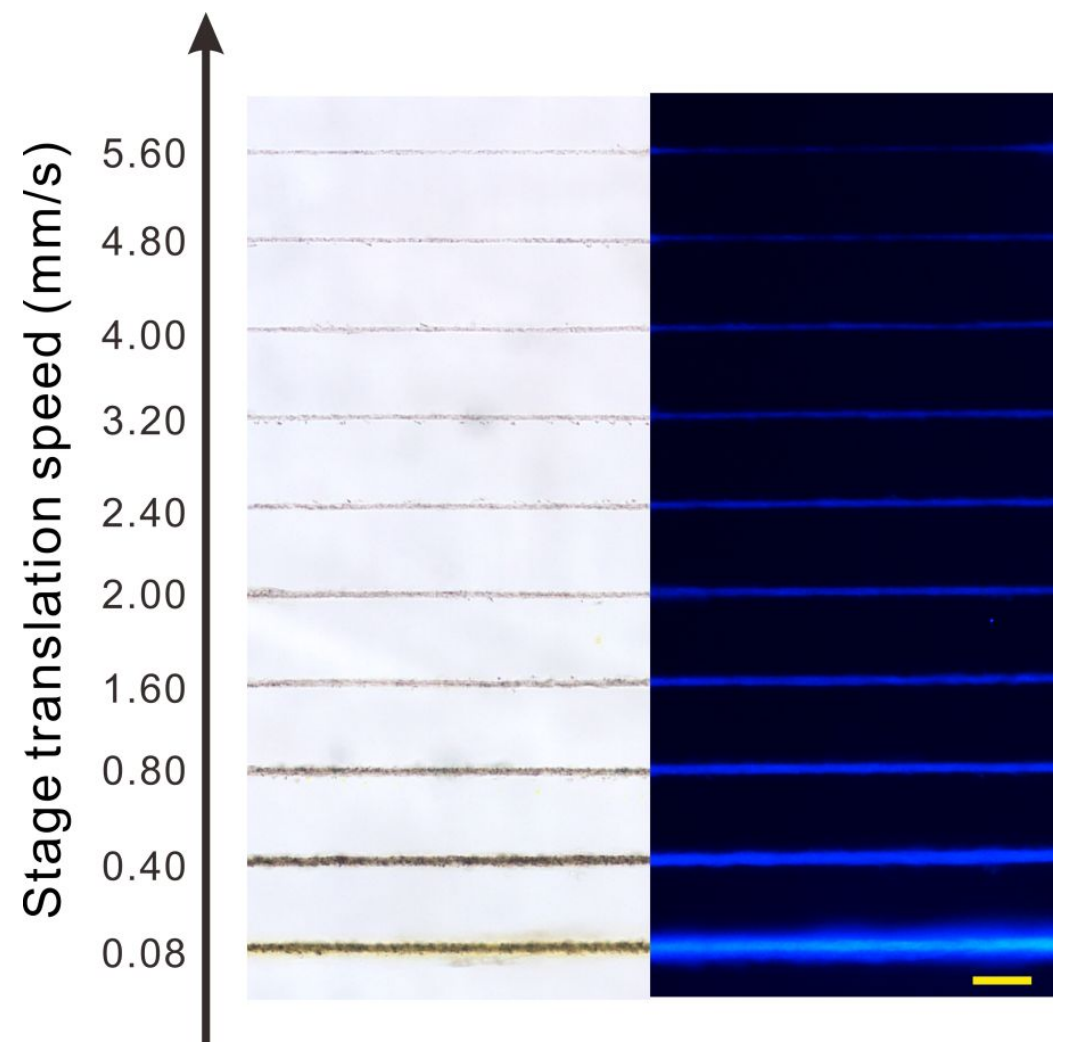

Figure S8. Optical images taken under visible light (left) and $365 \mathrm{~nm}$ UV light (right) for fs laser writing lines fabricated at a power density of $83 \times 10^{2} \mathrm{~kW} / \mathrm{cm}^{2}$ using different stage displacement speed (after annealed at $450{ }^{\circ} \mathrm{C}$ for $1 \mathrm{~h}$ ). Scale bars: $100 \mu \mathrm{m}$. 


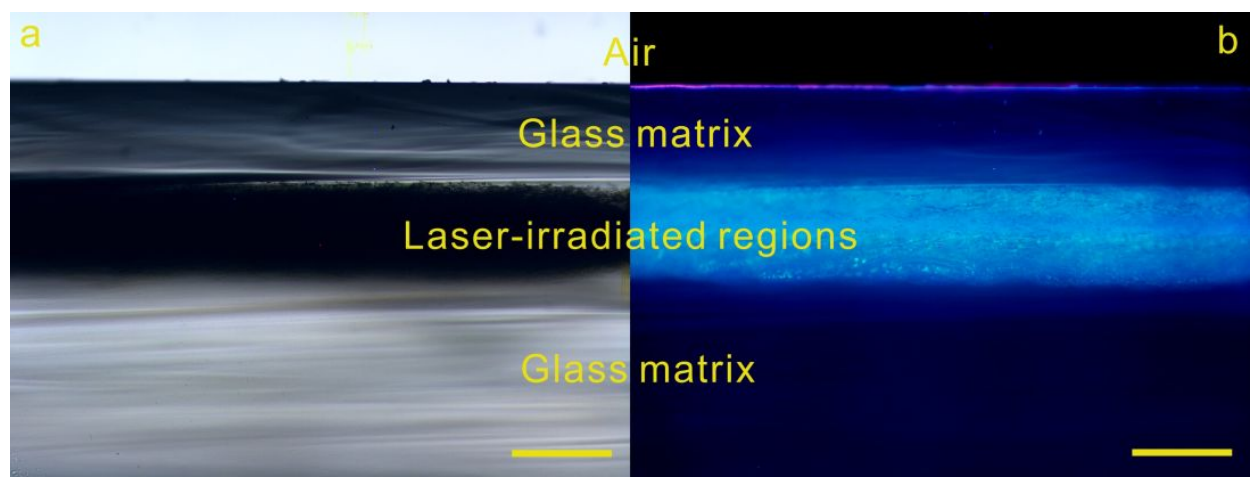

Figure S9. Optical images of cross section of the laser-irradiated regions under natural light (a) and $365 \mathrm{~nm}$ UV light (b). The dark regions in a is the Scale bars: $400 \mu \mathrm{m}$.
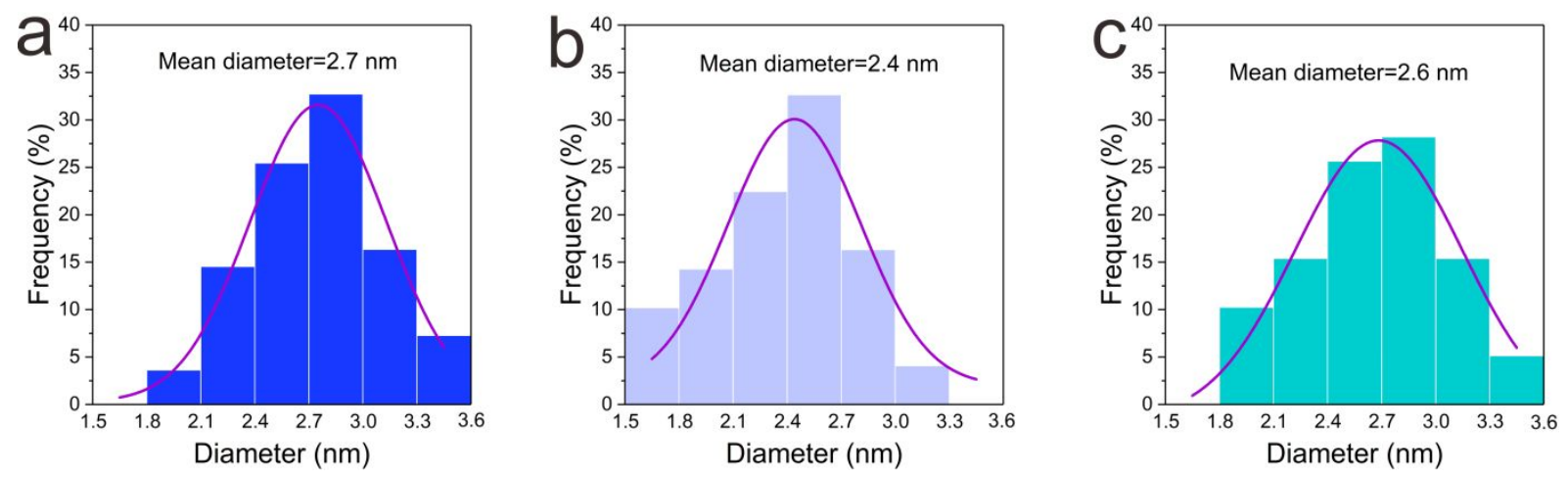

Figure S10. Size distribution of $\mathrm{CsPb}(\mathrm{Cl} / \mathrm{Br})_{3} \mathrm{NCs}$ formed in the glass as shown by the TEM images in Figure 3(e-g). a: $\mathrm{CsPb}(\mathrm{Cl} / \mathrm{Br})_{3}$, b: Erasing, c: Recovery. 

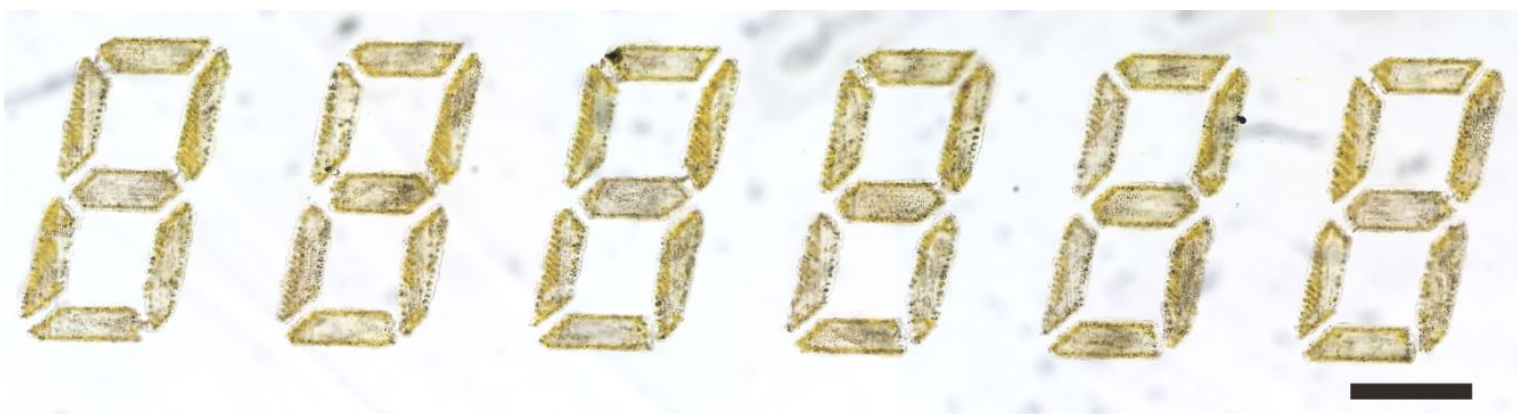

Figure. S11. Optical image of laser writing patterns after erasing and recovery process, showing no obvious structural damage appears after laser erasing and recovery process. Scale bar: $200 \mu \mathrm{m}$.
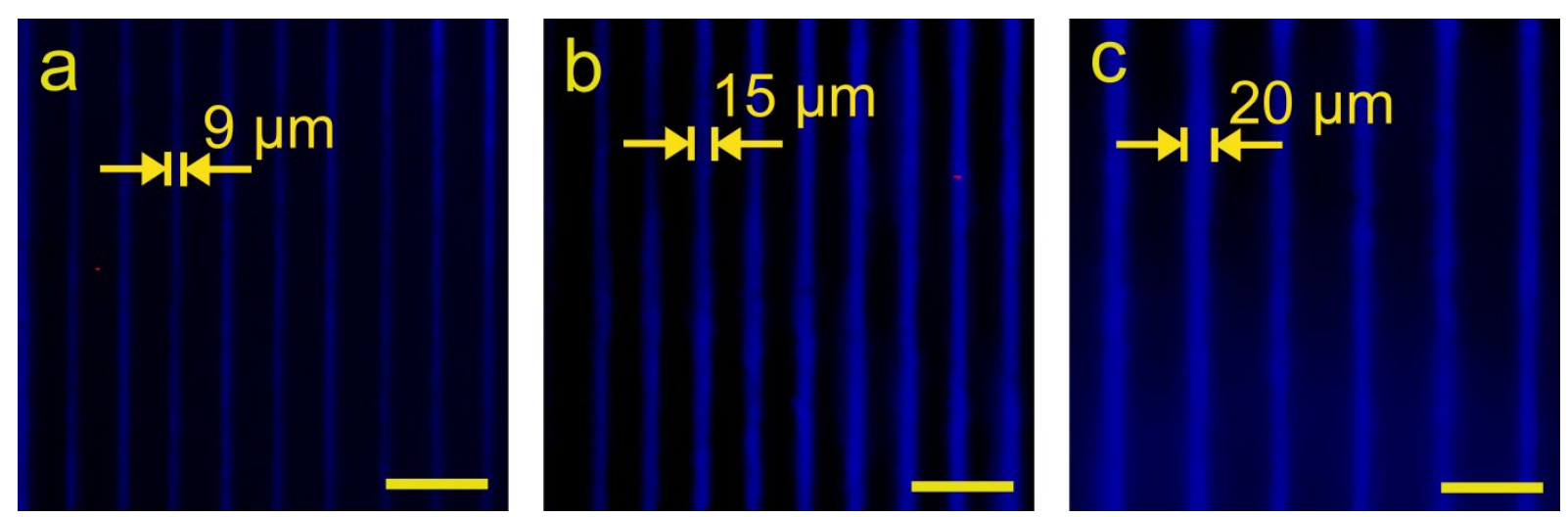

Figure S12. Fluorescence images of the laser-printed lines with different widths. Scale bar: $100 \mu \mathrm{m}$.

Table S1. Summary of average power, average power density, pulse energy and fluence of fs laser irradiation.

$\begin{array}{cccc}\begin{array}{c}\text { Average power } \\ (\mathrm{mW})\end{array} & \begin{array}{c}\text { Average power density } \\ \left(\times 10^{2} \mathrm{~kW} / \mathrm{cm}^{2}\right)\end{array} & \begin{array}{c}\text { Pulse energy } \\ (\mu \mathrm{J})\end{array} & \begin{array}{c}\text { Fluence } \\ \left(\times 10^{2} \mathrm{~J} / \mathrm{cm}^{2}\right)\end{array} \\ 287 & 138 & 287 & 138 \\ 230 & 111 & 230 & 111 \\ 173 & 83 & 173 & 83 \\ 116 & 56 & 116 & 56 \\ 59 & 28 & 59 & 28 \\ 30 & 14 & 30 & 14 \\ 7 & 3 & 7 & 3\end{array}$


Table S2. Summary of the laser fluence and exposure time that can form luminescent perovskite NCs. ' $\sqrt{ }$ ' means luminescence, ' $x$ ' means non-luminescence.

\begin{tabular}{|c|c|c|c|c|c|c|c|}
\hline Fluence $\left(\times 10^{2} \mathrm{~J} / \mathrm{cm}^{2}\right)$ & 3 & 14 & 28 & 56 & 83 & 111 & 138 \\
\hline Exposure time (s) & $\sqrt{ }$ & $\sqrt{ }$ & $\sqrt{ }$ & $\sqrt{ }$ & $\sqrt{ }$ & $\sqrt{ }$ & $\sqrt{ }$ \\
\hline 100 & $\sqrt{ }$ & $\sqrt{ }$ & $\sqrt{ }$ & $\sqrt{ }$ & $\sqrt{ }$ & $\sqrt{ }$ & $\sqrt{ }$ \\
\hline 10 & $\sqrt{ }$ & $\sqrt{ }$ & $\sqrt{ }$ & $\sqrt{ }$ & $\sqrt{ }$ & $\sqrt{ }$ & $\sqrt{ }$ \\
\hline 1 & $\times$ & $\sqrt{ }$ & $\sqrt{ }$ & $\sqrt{ }$ & $\sqrt{ }$ & $\sqrt{ }$ & $\sqrt{ }$ \\
\hline 0.1 & $\times$ & $\times$ & $\times$ & $\sqrt{ }$ & $\sqrt{ }$ & $\sqrt{ }$ & $\sqrt{ }$ \\
\hline 0.01 & $\times$ & $\times$ & $\times$ & $\times$ & $\sqrt{ }$ & $\sqrt{ }$ & $\sqrt{ }$ \\
\hline 0.001 & & & & & & & \\
\hline
\end{tabular}

\section{Reference}

1. Guo, Q.; Yao, Y.; Luo, Z. C.; Qin, Z.; Xie, G.; Liu, M.; Kang, J.; Zhang, S.; Bi, G.; Liu, X.; Qiu, J. Universal Near-Infrared and Mid-Infrared Optical Modulation for Ultrafast Pulse Generation Enabled by Colloidal Plasmonic Semiconductor Nanocrystals. ACS Nano 2016, 10, 9463-9469. 